ISSN 0258-7122 (Print), 2408-8293 (Online)

Bangladesh J. Agril. Res. 44(3): 501-512, September 2019

\title{
GENOTYPE AND ENVIRONMENT INTERACTION OF SWEETPOTATO VARIETIES
}

\author{
S. SultanA ${ }^{1}$, H. C. Mohanta 2 , Z. Alam $^{3}$ \\ S. NAZNIN ${ }^{4}$ AND S. BEGUM ${ }^{5}$
}

\begin{abstract}
The article presents results of additive main effect and multiplicative interaction (AMMI) and genotype $(\mathrm{G})$ main effect and genotype by environment (GE) interaction $(\mathrm{G} \times \mathrm{GE})$ biplot analysis of a multi environmental trial (MET) data of 15 sweetpotato varieties released from Bangladesh Agricultural Research Institute conducted during 2015-2018. The objective of this study was to determine the effects of genotype, environment and their interaction on tuber yield and to identify stable sweetpotato genotypes over the years. The experimental layout was a randomized complete block design with three replications at Gazipur location. Combined analysis of variance (ANOVA) indicated that the main effects due to genotypes, environments and genotype by environment interaction were highly significant. The contribution of genotypes, environments and genotype by environment interaction to the total variation in tuber yield was about $60.16,10.72$ and $12.82 \%$, respectively. The first two principal components obtained by singular value decomposition of the centred data of yield accounted for $100 \%$ of the total variability caused by $\mathrm{G} \times \mathrm{GE}$. Out of these variations, $\mathrm{PC} 1$ and $\mathrm{PC} 2$ accounted for $71.5 \%$ and $28.5 \%$ of variability, respectively. The study results identified BARI Mistialu- 5, BARI Mistialu- 14 and BARI Mistialu- 15 as the closest to the "ideal" genotype in terms of yield potential and stability. Varieties 'BARI Mistialu- 8, BARI Mistialu- 11 and BARI Mistialu- 12' were also selected as superior genotypes. BARI Mistialu- 3 and BARI Mistialu- 13 was comparatively low yielder but was stable over the environment. Among them BARI Mistialu-12, BARI Mistialu-14 and BARI Mistialu-15 are rich in nutrient content while BARI Mistialu- 8 and BARI Mistialu-11 are the best with dry matter content and organoleptic taste. Environments representing in $1^{\text {st }}$ and $3^{\text {rd }}$ year with comparatively short vectors had a low discriminating power and environment in $2^{\text {nd }}$ year was characterized by a high discriminating power.
\end{abstract}

\section{Introduction}

Sweetpotato (Ipomoea batatas L.) is used in a variety of ways for food, feed and processed products, with the principal uses varying by region. The literature on nutritional value of cooked and fried sweetpotatoes as well as processing

\footnotetext{
${ }^{1 \& 4}$ Scientific Officer (Plant Breeding), Tuber Crops Research Centre, Bangladesh Agricultural Research Institute (BARI), Gazipur-1701, ${ }^{2}$ Principle Scientific Officer, Tuber Crops Research Centre, BARI, Gazipur-1701, ${ }^{3}$ Scientific Officer, Tuber Crops Research Centre, BARI, Gazipur-1701, ${ }^{5}$ Scientific Officer, Plant Breeding Division, BARI, Gazipur-1701, Bangladesh.
} 
sweetpotato into food products such as bread, ready-to-eat breakfast, french fries, syrup, starch and beverages was comprehensively reviewed by Woolfe (1992), Bovel-Benjamin (2007) and Padmaja (2009). In developing countries, the crop is mainly grown for homestead food and feed use and to sell to local markets for fresh consumption. Use of both vines and roots for pig feeding is important in China, Vietnam and Papua New Guinea (Peters, 2004). Padmaja (2009) provides details on use of the crop for cattle, poultry and fish feed.

Sweetpotato was domesticated in tropical America about $6000 \mathrm{BC}$ and reached Polynesia, Hawaii and New Zealand naturally or by early seafarers in preColumbian times. The Spanish introduced the crop to the Philippines in the 16th century, from whence it spread to other islands and the Asian main land. By 1594, the crop was recorded in south China, where it was promoted to mitigate drought during the Qing Dynasty (ruling from 1644 to 1912). Portuguese seafarers introduced the crop into western Mediterranean Europe, Africa, India and parts of South-east Asia (O'Brien, 1972; Yen, 1976; Jia, 2013). According to the Food and Agriculture Organization (FAO) of the United Nations, sweetpotato is currently cultivated in 117 countries in all tropical and subtropical regions of the world, with 112 million metric ton (MT) of production in 2017. Asia is the world's largest sweetpotato producing region, with about $70.5 \%$ of annual production (FAOSTAT, 2017).

Trends in area cultivated from 2000 to 2016 (Fig. 1), notably show declines in Bangladesh (from 41.28 to 24.89 thousand ha). The total production decreased accordingly from 3,83,000 to 2,59,372 MT (FAOSTAT 2017). But storage root yield trends for the same period show slight increases (Fig. 1). Thus, there is significant potential to increase national yields through the use of improved cultural practices and varieties. For developed countries, about $50 \%$ of yield progress across crops is usually attributed to breeding progress (Wricke and Weber, 1986).

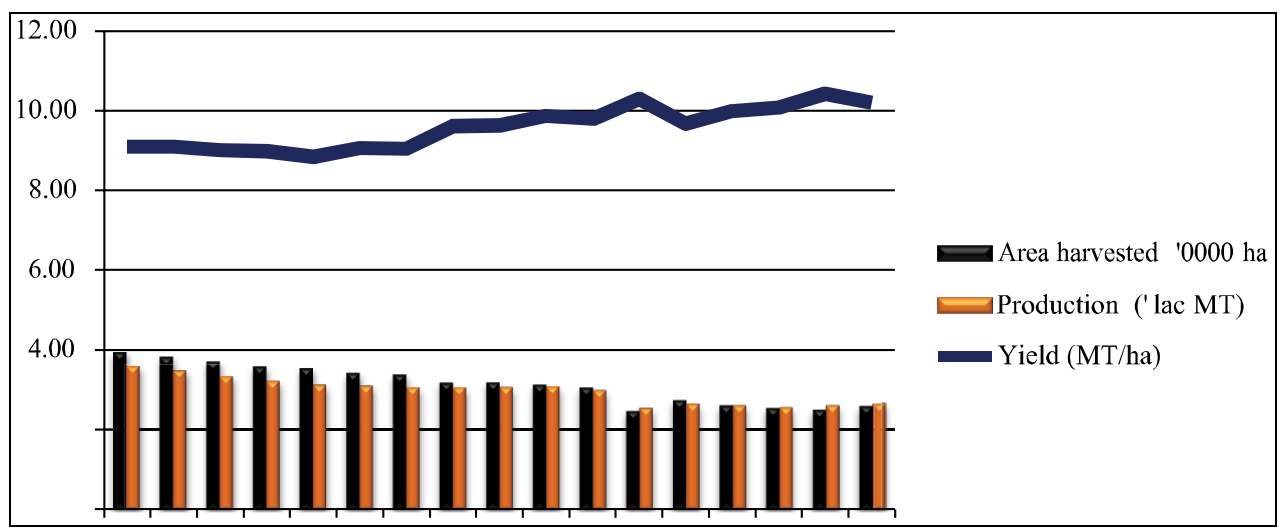

Fig. 1.Sweetpotato production in Bangladesh 
In Bangladesh, in spite of having different technologies the crops like sweetpotato are being pushed to marginal areas. Major reason is farmers are not properly acknowledged with high yielding variety as well as their nutritional status. Awareness of the high nutritional value of sweetpotato is increasing consumer demand among health conscious consumers in many other countries (USDA, 2015). Orange-fleshed sweetpotato (OFSP) can be used effectively to combat vitamin A deficiency (VAD) among vulnerable populations (Low et al., 2007; Hotz et al., 2011). Thus, sweetpotato can play an important role in the context of food security in Bangladesh. Tuber Crops Research Centre (TCRC) already has developed sixteen (16) sweetpotato varieties and some other promising lines are in the process of recommendation and release. However there is no target based recommendation available for sweetpotato production. Considering this, we went for a fine tuning of our varietal data and tried to make it more target oriented.

With this view, the objective of this study was assessment of variations in yield performance of sweetpotato varieties across years based on the AMMI and GGE biplot and identification of the most valuable genotypes. The basic cause of difference in the performance of genotypes over environments is the occurrence of genotype by environment interaction (Gedif, Yigzaw, 2014). The best tool for estimating G and GE effects is multi environment trials (METs). METs are an optimal method to select better genotypes for any specific environment and to identify genotypes that consistently realize their genetic potential in a wide range of environments.

Data from METs are usually quite large, and it is difficult to deduce general patterns of such data without graphical representation. Yan et al. (2000) developed the GGE biplot technique for graphical analysis of multi environment trial data. GGE biplot analysis considers that only the $\mathrm{G}$ and GE effects are relevant and that they need to be considered simultaneously when evaluating genotypes. The GGE biplot has therefore been used in crop variety trials to effectively identify the best performing genotype across environments, to identify the best genotypes for mega-environment delineation, whereby specific genotypes can be recommended for specific mega-environments, and to evaluate the yield and stability of genotypes (Yan, Kang, 2003; Yan, Tinker, 2006). An additive main effect and multiplicative interaction (AMMI) model is also commonly used to analyse GE interaction during yield trials.

\section{Materials and methods}

The experiment was conducted at Tuber Crops Research Centre (TCRC) in Gazipur during 2015-18. Fifteen (15) varieties of BARI released sweetpotato were included in the study. Vines were planted on $18^{\text {th }}, 15^{\text {th }}$ and $22^{\text {nd }}$ of November in three consecutive years during 2015-2017 in the field having plot 
size $3.0 \times 3.0 \mathrm{~m}$. The crop was fertilized with $250-280 \mathrm{~kg} / \mathrm{ha}$ urea, $140-170 \mathrm{~kg} / \mathrm{ha}$ TSP, 230-260 kg/ha MOP, 60-80 kg/ha gypsum, $10-12 \mathrm{~kg} / \mathrm{ha}$ zinc sulphate, $90-$ $120 \mathrm{~kg} / \mathrm{ha}$ magnesium sulphate, $6-8 \mathrm{~kg} / \mathrm{ha}$ boric acid and 10,000 kg/ha cowdung. All cowdung, TSP, gypsum, zinc sulphate, boric acid and half urea \& MP should be applied during final land preparation. Rest of the urea and MP should be applied after 35-40 DAP in furrow system. Harvesting time were $17^{\text {th }}, 20^{\text {th }}$ and $25^{\text {th }}$ March of 2016, 2017 and 2018 accordingly.

Both qualitative and quantitative data were collected in the study. The qualitative data included predominant skin colour, predominant flesh colour, sweetness, fibreness and texure etc. Sweetness were evaluated by organoleptic taste, where $\leq 3=$ slightly sweet, $4-6=$ moderately sweet, $6 \leq=$ highly sweet. In case of fibreness, $\leq 3=$ high fibre content, $4-6=$ moderate fibre content, $6 \leq=$ low fibre content and texure marked as $\leq 3=$ highly moist, $4-6=$ moderately dry, $6 \leq$ =highly dry.

The quantitative data included root dry matter content, expressed as percentage of root dry weight $(\mathrm{g})$ to fresh root weight $(\mathrm{g})$. Samples (100-200 g) were taken from roots of representative plants in a plot and the roots were cut into smaller pieces and oven dried at $70{ }^{\circ} \mathrm{C}$ for $72 \mathrm{~h}$. Fresh root yield, expressed as harvested fresh roots weight of $9 \mathrm{~m}^{2}$ converted to ton per hectare. Data were processed and analyzed using Cropstat 7.2 program and PB Tools 1.4.

The $\beta$-carotene content was estimated according to the method of the Association of Official Analytical Chemists (AOAC,1980) in Post Harvest Technology Division of BARI . In to a conical flask containing $50 \mathrm{ml}$ of $95 \%$ ethanol, $10 \mathrm{~g}$ of the macerated sample was placed and maintained at $70-80^{\circ} \mathrm{C}$ in a water bath for 20 minutes with periodic shaking. The supernatant was decanted, allowed to cool and its volume was recorded as initial volume. The ethanol concentration of the mixture was brought to $85 \%$ by adding $15 \mathrm{ml}$ of distilled water and it was further cooled in a container of ice water for about 5minutes. The mixture was transferred in to a separating funnel and $25 \mathrm{ml}$ of petroleum ether (pet-ether) was added and the cooled ethanol was poured over it. The funnel was swirled gently to obtain a homogenous mixture and it was later allowed to stand until two separate layers were obtained. The bottom layer was run off into a beaker while the top layer was collected in to a $250 \mathrm{ml}$ conical flask. The bottom layer was transferred in to the funnel and re-extracted with $10 \mathrm{ml}$ pet-ether for 5-6 times until the extract became fairly yellow. The entire pet-ether was collected in to $250 \mathrm{ml}$ conical flask and transferred in to separating funnel for re-extraction with $50 \mathrm{ml}$ of $80 \%$ ethanol. The final extract was measured and poured in to sample bottles for further analysis. The absorbance of the extracts was measured using a spectrophotometer (model 22UV/VIS) at a wavelength of $451 \mathrm{~nm}$. Samples of each extract were placed in cuvettes and readings were taken when the figure in 
the display window became steady. The operation was repeated 5-6 times for each sample and average readings were recorded. The concentration of $\beta$ carotene was calculated using Bear-Lamberts Law, which states that the absorbance (A) is proportional to the concentration(C) of the pigment, as represented by the equation:

$\mathrm{A} \infty \mathrm{L}$

(if concentration(C) is constant).

$\mathrm{A}=\mathrm{ECL} ; \mathrm{C}=\mathrm{A} / \mathrm{EL}$

\author{
Where: $\quad \mathrm{C}=$ concentration of carotene \\ $\mathrm{A}=$ absorbance \\ $\mathrm{E}=$ extinction coefficient \\ $\mathrm{L}=$ thickness of cuvettes (path length) \\ $=1 \mathrm{~cm} \mathrm{E}$ of $\beta$-carotene $=1.25 \times 104 \mu \mathrm{g} / \mathrm{l}$
}

Table 1. Meteorological conditions during sweetpotato growing season in three consecutive year in Gazipur.

\begin{tabular}{l|c|l|c|c|c|c}
\hline \multirow{2}{*}{ Month } & \multicolumn{2}{|c|}{$2015-16$} & \multicolumn{2}{c|}{$2016-17$} & \multicolumn{2}{c}{$2017-18$} \\
\cline { 2 - 7 } & $\begin{array}{c}\text { Air } \\
\text { Temperature } \\
\left({ }^{\circ} \mathrm{C}\right)\end{array}$ & $\begin{array}{c}\text { Precipitation } \\
\mathrm{mm}\end{array}$ & $\begin{array}{c}\text { Air } \\
\text { Temperature } \\
\left({ }^{\circ} \mathrm{C}\right)\end{array}$ & $\begin{array}{c}\text { Precipitation } \\
\mathrm{mm}\end{array}$ & $\begin{array}{c}\text { Air } \\
\text { Temperature } \\
\left({ }^{\circ} \mathrm{C}\right)\end{array}$ & $\begin{array}{c}\text { Precipitation } \\
\mathrm{mm}\end{array}$ \\
\hline November & 23.79 & 0 & 25.38 & 127 & 26 & 0 \\
December & 18.83 & 0 & 16.27 & 0 & 23 & 3 \\
January & 18.85 & 10 & 19.59 & 0 & 18 & 0 \\
February & 21.31 & 9 & 23.5 & 0 & 22 & 2 \\
March & 25.07 & 53 & 24.79 & 190 & 26 & 2 \\
\hline
\end{tabular}

\section{Results and Discussion}

Table 2 shows the phenotypic characteristics of sweetpotato varieties used in this study. All the plants are semi-erect to semi spreading type. The skin color of the tuber varied from cream color to pink color while their flesh color varied from light yellow to deep orange. The shape of tuber also varied from oval to long irregular form.

The yield capacity of the varieties varied both across environmental conditions, suggesting influence of the environmental factor (Table 3). The analysis of variance showed that the effects of genotype $(\mathrm{G})$, environment $(\mathrm{E})$ and their interaction $(\mathrm{G} \times \mathrm{E})$ on grain yield were statistically significant (Table 4). The ANOVA for tuber yield revealed that genotype, environment and GE interaction effects accounted for $60.16 \%, 10.72 \%$ and $12.82 \%$ of the total sum of squares, respectively. The E portion in multi environment trials (METs) is known to be the smallest among all sources of variation, which is regarded as irrelevant for genotype evaluation (Yan and Kang, 2003). This is the reason that $\mathrm{E}$ is removed from the phenotypic data observed, which helps to concentrate on G and GE effects, which are relevant for genotype evaluation (Yan and Kang, 2003; Fan et al., 2007). 
Table 2. Description of 15 varieties of sweetpotato tested

\begin{tabular}{|c|c|c|c|c|c|c|c|c|}
\hline \multirow[t]{2}{*}{ Variety } & \multirow[t]{2}{*}{ Source } & \multirow[t]{2}{*}{ Year } & & \multicolumn{3}{|c|}{ Tuber characteristics } & \multirow[b]{2}{*}{$\mathrm{BCC}$} & \multirow[b]{2}{*}{$\mathrm{DM} \%$} \\
\hline & & & Skin color & Shape & $\begin{array}{c}\text { Skin } \\
\text { smooth } \\
\text {-ness }\end{array}$ & Flesh color & & \\
\hline BARI Mistialu-1 & Philippines & 1985 & cream & Elliptic & MS & Pale yellow & 0.99 & 29.82 \\
\hline BARI Mistialu-2 & Taiwan & 1985 & red & Elliptic & MS & Dark orange & 13.59 & 21.67 \\
\hline BARI Mistialu-3 & $\begin{array}{c}\text { local } \\
\text { collection }\end{array}$ & 1988 & white & Long Elliptic & MS & Cream & 0.03 & 28.56 \\
\hline BARI Mistialu-4 & Hybridiz $^{\mathrm{n}}$ & 1994 & Pale orange & Obovate & MS & Dark orange & 7.23 & 27.97 \\
\hline BARI Mistialu-5 & Hybridiz $^{\mathrm{n}}$ & 1994 & Red & Oblong & $S$ & Pale orange & 4.41 & 22.79 \\
\hline BARI Mistialu-6 & CIP & 1998 & Pale orange & Oblong & MS & Pale orange & 1.04 & 24.15 \\
\hline BARI Mistialu-7 & CIP & 1998 & white & Oblong & MS & Pale yellow & 0.69 & 28.99 \\
\hline BARI Mistialu-8 & CIP & 2008 & pink & Long irregular & MS & Pale yellow & 1.76 & 35.82 \\
\hline BARI Mistialu-9 & CIP & 2008 & red & Long irregular & MS & Int .orange & 4.41 & 20.04 \\
\hline BARI Mistialu-10 & Hybridiz $^{n}$ & 2013 & white & Oblong & MS & Dark cream & 0.12 & 27.14 \\
\hline BARI Mistialu-11 & Hybridiz $^{\mathrm{n}}$ & 2013 & pink & Long elliptic & MS & Cream & 0.04 & 35.70 \\
\hline BARI Mistialu-12 & CIP & 2013 & cream & Long oblong & MS & Pale orange & 5.46 & 21.93 \\
\hline BARI Mistialu-13 & CIP & 2013 & yellow & Long oblong & MS & Int. orange & 6.12 & 29.35 \\
\hline BARI Mistialu-14 & CIP & 2018 & pink & Long irregular & MS & Dark orange & 14.67 & 25.06 \\
\hline BARI Mistialu-15 & CIP & 2018 & pink & Long irregular & MS & Dark orange & 12.35 & 21.94 \\
\hline
\end{tabular}

$\mathrm{BCC}=\beta$-carotene contentmg $100 \mathrm{~g}^{-1}$, MS=Medium smooth, $\mathrm{S}=$ Smooth, DM\%= Dry matter \%

Table 3. Tuber yield capacity of BARI sweetpotato varieties in the multi environment trial, $\mathrm{t} \mathrm{ha}^{-1}$

\begin{tabular}{ccccccc}
\hline Variety code & Variety & $2015-16$ & $2016-17$ & $2017-18$ & Mean \\
\hline 1 & BARI Mistialu-1 & 11.63 & 11.85 & 18.31 & 13.93 \\
2 & BARI Mistialu-2 & 17.86 & 16.00 & 13.62 & 15.82 \\
3 & BARI Mistialu-3 & 12.95 & 6.000 & 9.294 & 9.41 \\
4 & BARI Mistialu-4 & 15.23 & 14.85 & 11.12 & 13.73 \\
5 & BARI Mistialu-5 & 21.83 & 15.56 & 15.46 & 17.61 \\
6 & BARI Mistialu-6 & 15.61 & 12.44 & 9.821 & 12.62 \\
7 & BARI Mistialu-7 & 14.14 & 10.26 & 11.31 & 11.90 \\
8 & BARI Mistialu-8 & 26.60 & 21.70 & 15.95 & 21.41 \\
9 & BARI Mistialu-9 & 15.15 & 15.67 & 12.12 & 14.31 \\
10 & BARI Mistialu-10 & 25.21 & 11.59 & 17.50 & 18.10 \\
11 & BARI Mistialu-11 & 33.87 & 13.96 & 27.10 & 24.97 \\
12 & BARI Mistialu-12 & 38.93 & 29.30 & 31.14 & 33.12 \\
13 & BARI Mistialu-13 & 10.08 & 10.41 & 8.065 & 9.517 \\
14 & BARI Mistialu-14 & 23.76 & 13.59 & 16.34 & 17.89 \\
15 & BARI Mistialu-15 & 22.06 & 14.45 & 17.65 & 18.05 \\
\hline
\end{tabular}


Table 4. Analysis of variance (ANOVA) for effects of genotype, environment and their interaction on sweetpotato tuber yield during 2015-2018.

\begin{tabular}{lccccc}
\hline Source & Degree of freedom & Sum of squares & Mean square & $\%$ SST \\
\hline Genotype $(\mathrm{G})$ & 14 & 1600.20 & $114.300^{* * *}$ & 60.16 \\
Environment $(\mathrm{E})$ & 2 & 285.114 & $142.557 * * *$ & 10.72 \\
$\mathrm{G} \times \mathrm{E}$ & 28 & 341.072 & $12.1811^{*}$ & 12.82 \\
Error & 116 & 433.3 & 3.7353 & \\
Total & & 2659.69 & & \\
\hline
\end{tabular}

$\%$ SST - percentage relative to the sum of squares total; *** - significant at the $0.1 \%$ level of probability

* - significant at the $5 \%$ level of probability

The GGE biplot was constructed using the first two principal components (PC1 and PC2) derived from subjecting the data to singular-value decomposition. The GGE biplot graphically displays G plus GE of the MET data in a way that facilitates visual variety evaluation and mega-environment identification. Only two PC (PC1 and PC2) are retained in the model because such a model tends to be the best model for extracting patterns (Yan, 2002; Yan et al., 2007; Yan, 2014). Via this model, PC1 and PC2 can be readily displayed in a two dimensional biplot so that the interaction between each genotype and each environment can be visualized (Fig. 3).

The first two principal components obtained by singular value decomposition of the centred data of tuber yield accounted for $100 \%$ of the total variability caused by $\mathrm{G}+\mathrm{GE}$. Out of these variations, PC1 and PC2 accounted for $71.5 \%$ and 28.5 $\%$ of variability, respectively (Fig $3 \& 4$ ).

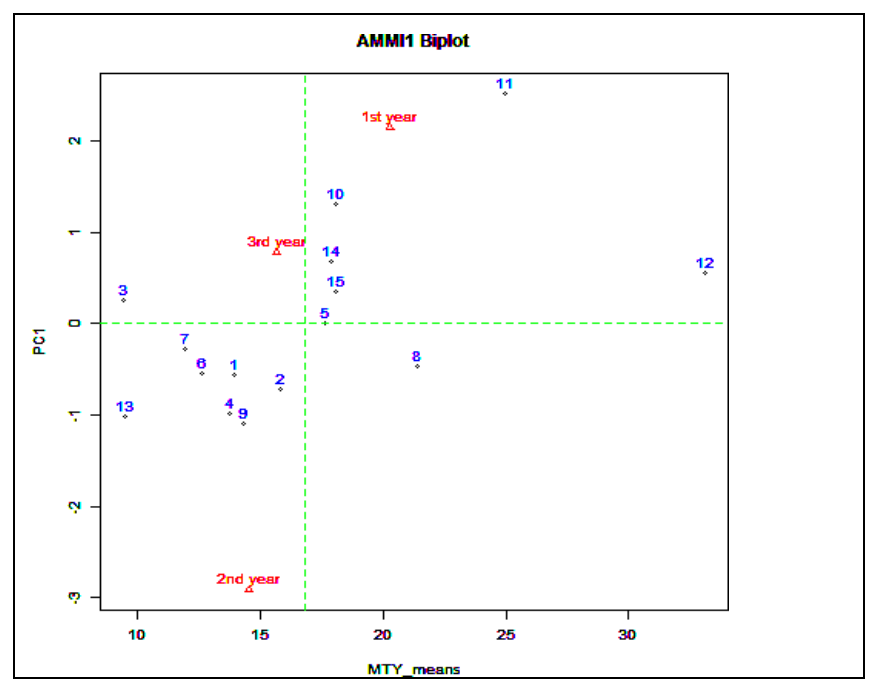

Fig. 2. AMMI biplot of the first interaction (IPCA1) score plotted against mean tuber yield (t/ha)) 
In AMMI biplot model, some genotype in one environment exposed higher yield than in other environment. Individual genotype performance can be measured based on their position relative to the $\mathrm{X}$ and $\mathrm{Y}$ axis. The suitable genotype are those which have high yield with stable performance over the year. Year 1 and year 2 were highly varied for tuber yield. Year 1 represented the most favorable environment and the environment of $2^{\text {nd }}$ year was most unfavorable for tuber yield (Fig 2). According to Fig. 2, genotype no. 3, 5, 7 and 15 have differences for tuber yield only for main (additive) effects. They had low interaction and thus they were stable. These varieties can be recommended for all environments. While the genotype no. 1, 2, 6, 8 and 14 have main and interaction effects. The other genotypes had high interaction with the environments hence they were specific to certain environment.

The IPCA1 scores were schemed against the IPCA2 scores for supplementary assessment of adaptation for tuber yield (Fig. 3). According to Fig. 3 the genotypes 3, 5,7 and 15 were stable over years for tuber yield as located within the circle. The performances of other genotypes were unstable due to their dispersed position.

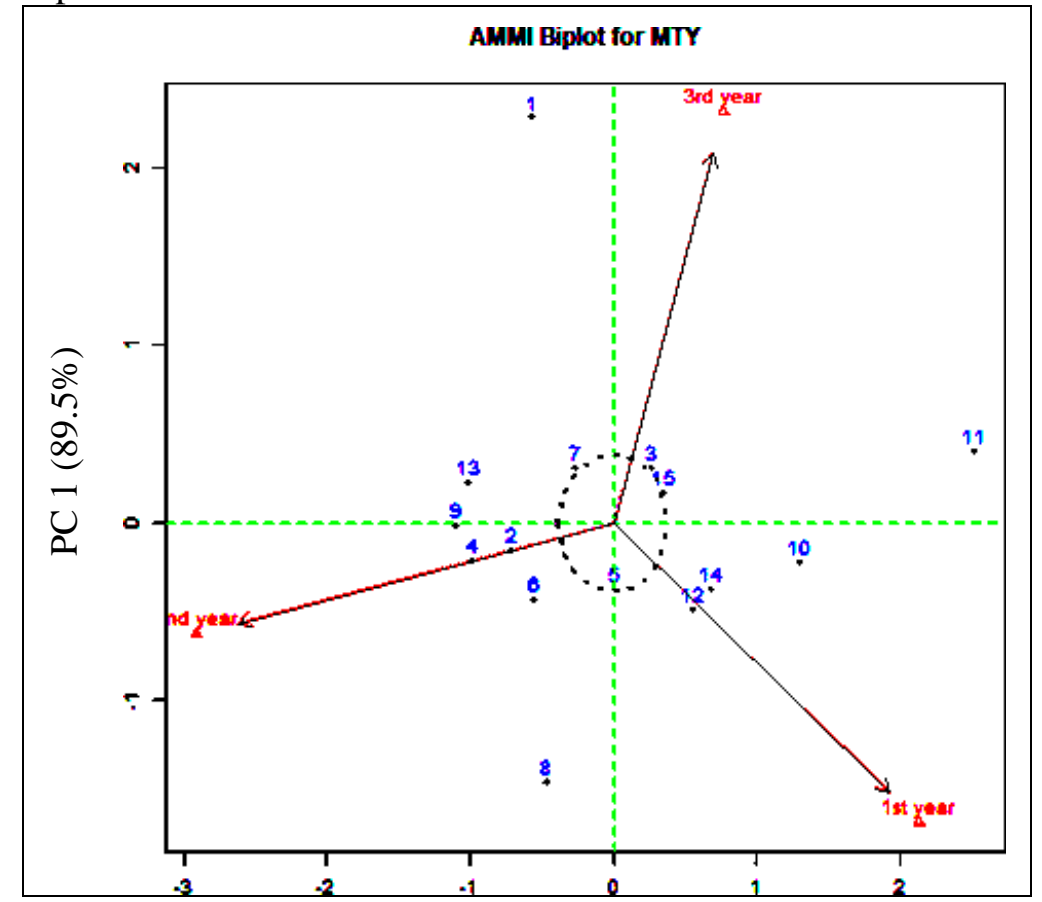

Fig. 3. AMMI Biplot 2 interaction (IPCA1 and IPCA2) of 15 sweetpotato varieties in three consecutive years for tuber yield

In contrast, the genotype main effect plus genotype-environmental interaction (GGE) biplot model provides better graphical illustration and identify the performance of cultivars under multiple stress environment, ideal cultivars and 
mega environment. In other words, the GGE biplot analysis was used for estimation of discriminating power and representativeness of an environment as a test one for assessing genotypes (Fig.4). The graph "which-won-where" enables to identify potential mega- environments (Yan et al., 2000 and Yan and Hunt, 2001). GGE biplot allows visualizing environment vectors lengths, which are proportional to standard deviations of genotype yields in a corresponding environment. If the marker of a test environment is close to the biplot centre, i.e. has a short vector, all genotypes in it are similar, and this environment is not informative about their differentiation. Thus, environments representing in $1^{\text {st }}$ and $3^{\text {rd }}$ year with comparatively short vectors had a low discriminating power, and environment in $2^{\text {nd }}$ year was characterized by a high discriminating power (Fig. 4).

The genotypes that are utmost from the origin are connected with a straight line forming a polygon. The lines starting from the origin divide the polygon into several sectors. The genotype at the vertex of the polygon performs the best in the environment falling within the sectors (Yan 2002). The locations within one sector are the ones where the certain genotype had the best yield and can be considered as mega- environments only for that genotype. Which-won-where biplots for tuber yield were presented in Fig. 4.

Genotype no. 8 and 12 were high tuber yielder in 2016-17 but genotype no.11 was more stable in mega environments (Fig. 4). Genotype no. 5, 14 and 15 are more stable to different environment.

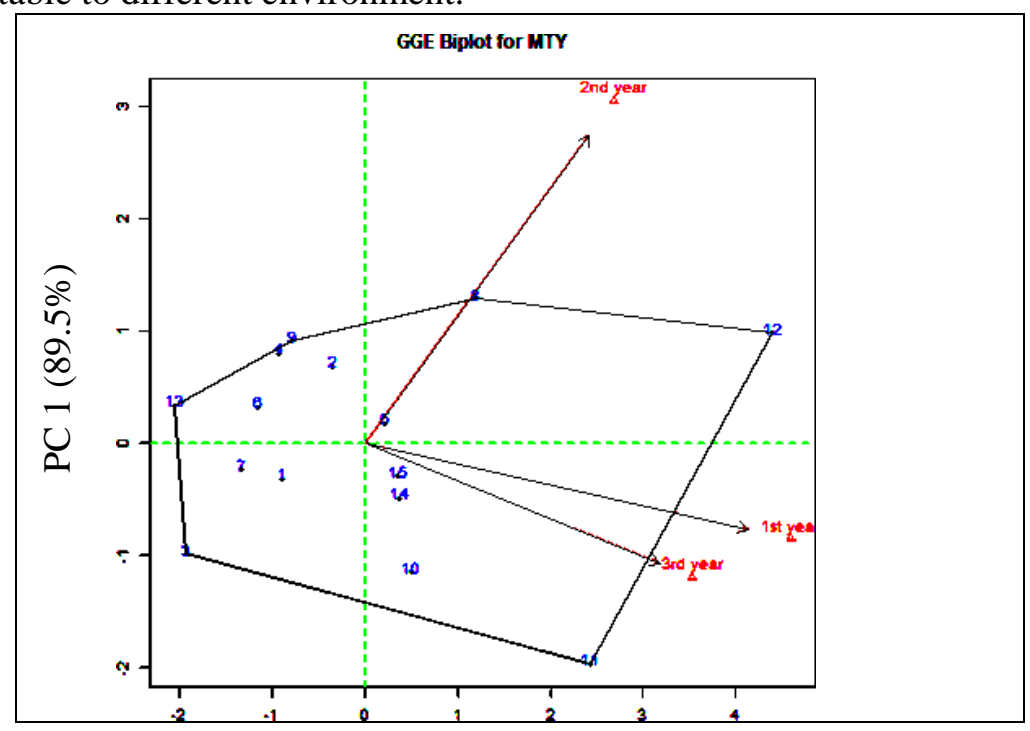

Fig. 4. GGE biplot showing "which won where" for tuber yield of 15 sweetpotato varieties in three consecutive years . 
However, many breeders rank yield and quality equally, because clones that do not meet consumer quality preferences are simply not permanently adopted. With respect to the 'dessert type' in Asia and the Pacific, yield was ranked number five after: (i) eating qualities; (ii) nutritional value; (iii) appearance and uniformity; and (iv) early maturity (Lin et al., 1983). However, dry matter, starch content and sugars do not exclusively control taste and flavor. Hence, storage roots must be assessed by eating for quality breeding. Sensory attributes of sweetpotato hybrid clones are shown in Table 5. Statistical analysis was not done on these parameters. From mean value, BARI Mistialu-11 (17), BARI Mistialu-8 (15) gave the best mouth feel and got the superiority in terms of overall acceptability. BARI Mistialu-14 (13) also has good taste even contrasted with high betacarotene $\left(14.67 \mathrm{mg} 100 \mathrm{~g}^{-1}\right)$. Yellow and orange colour in sweetpotato storage roots is determined by carotenoids. Fortunately, the proportion of $\beta$-carotene as dominant provitamin A is greater than $80 \%$ among the total carotenoid content in OFSP (Woolfe, 1992). For this reason, flesh colour alone can be used to predict beta-carotene content of storage roots. In the ways of this aspect, most of the varieties have extra bonus of nutrition.

Table 5. Mean sensory evaluation of sweetpotato varieties

\begin{tabular}{cc|c|c|c|c}
\hline Variety & Boiled Color & $\begin{array}{c}\text { Fiberness } \\
\text { (a) }\end{array}$ & $\begin{array}{c}\text { Sweetness } \\
\text { (b) }\end{array}$ & $\begin{array}{c}\text { Texture } \\
\text { (c) }\end{array}$ & $\begin{array}{c}\text { Overall } \\
\text { Acceptability Score } \\
(\mathrm{a}+\mathrm{b}+\mathrm{c})\end{array}$ \\
\hline BARI Mistialu-1 & Yellow & 5 & 4 & 3 & 12 \\
BARI Mistialu-2 & Orange & 4 & 2 & 2 & 8 \\
BARI Mistialu-3 & Cream & 4 & 4 & 5 & 13 \\
BARI Mistialu-4 & Pale Orange & 3 & 4 & 3 & 10 \\
BARI Mistialu-5 & Pale Orange & 4 & 3 & 3 & 10 \\
BARI Mistialu-6 & Light yellow & 2 & 4 & 3 & 9 \\
BARI Mistialu-7 & Yellow & 3 & 3 & 5 & 11 \\
BARI Mistialu-8 & Yellow & 2 & 7 & 6 & 15 \\
BARI Mistialu-9 & Light orange & 2 & 3 & 3 & 8 \\
BARI Mistialu-10 & Yellow & 4 & 2 & 3 & 9 \\
BARI Mistialu-11 & Light yellow & 4 & 7 & 6 & 17 \\
BARI Mistialu-12 & Orange & 4 & 3 & 3 & 10 \\
BARI Mistialu-13 & Light orange & 3 & 3 & 3 & 9 \\
BARI Mistialu-14 & Deep orange & 3 & 5 & 5 & 13 \\
BARI Mistialu-15 & Deep orange & 3 & 4 & 4 & 11 \\
\hline
\end{tabular}

Fibreness : $\leq 3=$ High fibre content, $4-6=$ moderate fibre content, $6 \leq=$ Low fibre content Sweetness : $\leq 3=$ slightly sweet, $4-6=$ moderately sweet, $6 \leq=$ highly sweet, Texure: $\leq 3=$ Highly moist, $4-6=$ moderately dry, $6 \leq=$ highly dry 


\section{Conclusion}

In the current study, BARI Mistialu- 8, BARI Mistialu- 11 and BARI Mistialu12 were selected as superior genotypes. BARI Mistialu- 5, BARI Mistialu- 14 and BARI Mistialu- 15 were found stable for marketable tuber yield. The study also revealed that sweetpotato yield was highly influenced by the differences among genotypic effects, followed by genotype by environment interaction $(\mathrm{G} \times$ E) variable and cultivation environments. This study also clearly demonstrated that the GGE biplot model was effective for the determination of the magnitude and pattern of $\mathrm{G} \times \mathrm{E}$ effect and visualizing the yield potential and stability of sweetpotato genotypes as well as discriminating ability and representativeness of the test environments. Considering the seasonal variations, such stable genotypes were regarded to be climate smart and could be used as parents in a breeding programme. However, there is need to increase the number of sites to better reveal the difference among genotypes.

\section{References}

Bovel-Benjamin, A.C.2007. Sweetpotato: A review of its past, present and future role in human nutrition.

Advances in Food and Nutrition Research. 52:1-59.

Fan, X.M., M. S. Kang, H. Chen, Y. Zhang, J. Tan and C. Xu. 2007. Yield stability of maize hybrids evaluated in multi environment trials in Yunnan, China. Agronomy Journal. 99: 220-228.

FAOSTAT .2017. Available at: http://www.fao.org/faostat/en/\#data.

Gedif, M. and D.Yigzaw. 2014. Genotype by environment interaction analysis for tuber yield of potato (Solanum tuberosum L.) using a GGE biplot method in Amhara region, Ethiopia. Agricultural Sciences. 5: 239-249.

Hossain, M.M. and M.A. Siddique. 1985. Sweetpotato: Production, use and improvement (in bengali). Mrs, Hena Siddique, Bangladesh Agricultural University Campus, Mymensingh. pp.112.

Hotz, C., L. Abdelrahman, C. Sison, M. Moursi and C Loechl. 2011. A food composition table for central and eastern Uganda. Washington, DC: HarvestPlus.

Jia, R. 2013. Weather shocks, sweetpotatoes and peasant revolts in historical China. The Economic Journal. 124(575): 92-118.

Lin, S.S.M., C.R. Peet, D.M. Chen and H.F. Lo.1983. Breeding goals for sweetpotato in Asia and the Pacific - a survey of sweetpotato production and utilization. In: Martin, F.W. (ed.) Breeding new sweetpotatoes for the tropics. Proceedings of the American Society of Horticultural Science. 27(B): 42-60.

Low, J.W., M. Arimond, N. Osman, B. Cunguara, F. Zano and D. Tschirley. 2007. A food-based approach: Introducing orange-fleshed sweetpotatoes increased vitamin A intake and serum retinol concentrations in young children in rural Mozambique. Journal of Nutrition .137: 1320-1327. 
O'Brien, P.J. 1972. The sweetpotato: Its origin and dispersal. American Anthropologist. 74:343-365. Padmaja, G. 2009. Uses and nutritional data of sweetpotato. In: Loebenstein, G. and Thottappilly, G. (eds) The Sweetpotato. Springer Science + Business Media BV, Houten, The Netherlands. pp. 189- 234.

Peters, D. 2004. Use of sweetpotato in pig production in Asia: Agricultural and socioeconomic aspects. Pig News and Information. 25(1): 25N-34N.

United States Department of Agriculture (USDA).2015. Commodity highlight: Sweetpotatoes. Economic Research Service Situation and Outlook Report VGS-355SA1, Washington DC.

Woolfe, J.A. 1992. Sweetpotato: An untapped food resource. Cambridge University Press, Cambridge. Wricke, G. and W.E. Weber.1986. Quantitative genetics and selection in plant breeding.de Gruyter, Berlin.

Yan W. and M. S. Kang. 2003. GGE Biplot analysis: A graphical tool for breeders, geneticists and agronomists. CRC Press. Pp.271.

Yan, W. and N.A.Tinker.2006. Biplot analysis of multi-environment trial data: Principles and applications. Canadian Journal of Plant Science. 86: 623-645.

Yan, W and L.A. Hunt. 2002.Crop Science. 42: 21-30.

Yan, W. 2002. Singular value partitioning for biplot analysis of multi-environment trial data. Agronomy Journal. 4: 990-996.

Yan, W. 2014. Crop variety trials: Data management and analysis. Wiley-Blackwell, Hoboken, New Jersey, USA. pp. 349.

Yan, W. and L.A. Hunt. 2001. Interpretation of genotypex environment interaction for winter wheat yield in Ontario. Crop Science. 41: 19-25.

Yan, W., L.A. Hunt, Q. Sheng and Z. Szlavnics. 2000. Cultivar evaluation and mega environment investigation based on the GGE biplot. Crop Sci. 40: 597-605.

Yan, W., M.S. Kang, B. Ma, S. Woods, and P.L. Cornelius. 2007. GGE biplot vs. AMMI analysis of genotype-by-environment data. Crop Science. 47: 643-655.

Yen, D.E.1976. The sweetpotato. In: Simmonds, N.W. (ed.) Evolution of crop plants. Longman, New York. pp. 42-45. 